\title{
Correction to: The Oslo Opera House - Condition Analysis and Proposal for Cleaning, Protection and Maintenance of Exterior Marble
}

Pagona-Noni Maravelaki, Lucia Toniolo, Francesca Gherardi,

Chrysi Kapridaki, and Ioannis Arabatzis

\section{Correction to: \\ Chapter "The Oslo Opera House - Condition Analysis and Proposal for Cleaning, Protection and Maintenance of Exterior Marble" in: A. Moropoulou et al. (Eds.): Transdisciplinary Multispectral Modeling and Cooperation for the Preservation of Cultural Heritage, CCIS 962, https://doi.org/10.1007/978-3-030-12960-6_7}

The original version of this chapter contained an error in the third author's name. The spelling of Francesca Gherardi's name was incorrect in the header of the chapter. The author name has been corrected. 